\title{
A nested case-control study of lung cancer among silica exposed workers in China
}

\author{
Joseph K McLaughlin, Chen Jing-Qiong, Mustafa Dosemeci, Chen Rong-An, \\ Suzanne H Rexing, Wu Zhien, Frank J Hearl, Michael A McCawley, William J Blot
}

\begin{abstract}
In an attempt to assess whether silica induces lung cancer, a nested case-control study of 316 male lung cancer cases and 1352 controls was carried out among pottery workers and tungsten, copper-iron, and tin miners from five provinces in south central China. Exposure to dust and silica for each study subject was evaluated quantitatively by cumulative exposure measures based on historical industrial hygiene records. Measurements on confounders such as inorganic arsenic, polycyclic aromatic hydrocarbons (PAHs), and radon were also collected from the worksites. Information on cigarette smoking was obtained by interviews of the subjects or their next of kin. A significant trend of increasing risk of lung cancer with exposure to silica was found for tin miners, but not for miners working in tungsten or copper-iron mines. Concomitant and highly correlated exposures to arsenic and PAHs among tin miners were also found. Risk of lung cancer among pottery workers was related to exposure to silica, although the dose-response gradient was not significant. Risks of lung cancer were significantly increased among silicotic subjects in iron-copper and tin mines, but not in pottery factories or tungsten mines. The results of this study provide only limited support for an aetiological association between silica and lung cancer.
\end{abstract}

National Cancer Institute, Division of Cancer Etiology, Epidemiology and Biostatistics Program, Bethesda, Maryland 20892

J K McLaughlin, M Dosemeci, W J Blot

Tongji Medical University, School of Public Health, Department of Labor, Health and Occupational Diseases, Wuhan, People's Republic of China

J-Q Chen, R-A Chen, Z Wu

Westat Inc., Rockville, Maryland 20850

S H Rexing

National Institute for Occupational Safety and Health, Division of Respiratory Disease Studies, Morgantown, West Virginia 26505

F J Hearl, M A McCawley
Although evidence in laboratory animals appears sufficient to consider crystalline silica as carcinogenic, epidemiological evidence is not conclusive ${ }^{1-5}$ In an attempt to clarify the role of silica in the aetiology of lung cancer, we initiated a study of silica exposed workers at facilities in five provinces of central and south China, which historically have had heavy exposure to this mineral. By contrast with most earlier studies, the present report classifies each subject according to cumulative exposure to silica dust as well as to exposure to known lung carcinogens such as cigarette smoke, inorganic arsenic, polycyclic aromatic hydrocarbons (PAHs), and radon.

\section{Methods}

SUBJECT SELECTION

Twenty nine mines and factories from five provinces in China were included in the study. These were eight pottery factories and one clay mine in Jiangxi, Henan, and Hunan provinces; 10 tungsten mines in Jiangxi and Hunan provinces; six copper-iron mines in Hubei province; and four tin mines in Guangxi province. From these mines and factories a cohort of 68285 workers was assembled who were employed during the period 1 January 1972 to 31 December 1974. The workers were followed up for lung cancer mortality until 31 December 1989. All workers who died of lung cancer during this period were considered as cases in a case-control study; however, due to the small number of lung cancer cases (11) among women in this mostly male ( $95 \%$ ) cohort, women were excluded from the analysis. Four (when possible) randomly selected workers individually matched on age (decade of birth) and mine or factory to each case served as controls. Controls must have survived to an age equal to or greater than the age at diagnosis of the corresponding case to be eligible. A questionnaire was administered to the study subject or his next of kin to obtain information on cigarette and other tobacco use, medical history, and demographic background.

\section{MORTALITY ASCERTAINMENT}

Vital status and cause of death were determined for each worker in the cohort. Employment records were 
the first source reviewed, as mines and factories in China keep information on the vital status of both current and pensioned employees. There is little opportunity to change work sites in China, as it is possible only with government approval. Employment records, therefore, are a good source for vital status information. Information on vital status was also sought from medical and death records at local hospitals. Further diagnostic information was obtained from local or regional hospitals for each decedent whose cause of death was listed as lung cancer. A panel of Chinese radiologists reviewed all $x$ ray films or $x$ ray film reports of lung cancer.

\section{SILICOSIS ASCERTAINMENT}

Since 1963, a national law mandated that workplaces in China with exposure to silica have a silicosis registry. ${ }^{6}$ All mines and factories in the study had one. Workers with silicosis are usually examined and $x$ ray films taken every two or three years to monitor their condition. Retired workers with this condition receive compensation for the rest of their lives.

\section{EXPOSURE ASSESSMENT}

A detailed quantitative exposure matrix was developed using information from work histories, historical industrial hygiene records, and a special monitoring program designed for this investigation.? Briefly, the industrial hygiene records of each mine and factory were reviewed for information on dust and silica levels starting in the 1950 s. A job title dictionary was developed for the 29 study sites in five major activities (underground mining, open cast mining, ore separation processing, pottery production, and other activities) that separated dust exposed from non-dust exposed jobs by calendar year based on facility records and the consensus of local mine and factory hygiene and engineering experts. These decisions were reviewed by both Chinese and United States industrial hygienists. The job title dictionary included 148 titles for the 29 study sites (659 facility and job title combinations). Historical information on exposure to dust and per cent free silica in dust, available since the $1950 \mathrm{~s}$, was collected for each facility at intervals of three years, along with recent and more limited information on confounding exposures such as radon, arsenic, PAHs, asbestos, nickel, talc, and cadmium. Exposures to asbestos, nickel, talc, and cadmium in the study sites were minimal and they were not evaluated in the analysis.

As well as historical exposure information, data on current exposure concentrations for total dust, per cent free silica and respirable and thoracic dust, and for the potential confounding agents were measured in each of the 29 mines and factories by both American and Chinese industrial hygienists. A comparison of Chinese and American sampling and measurement methods was also carried out, which indicated good agreement for total and respirable dust, and per cent free silica. ${ }^{8}$

\section{WORK HISTORY}

Work histories were obtained for lung cancer cases and their controls by abstracting their complete employment records from mine or factory files. These records were merged with historical and current exposure data based on facility, job title, and calendar year to create an exposure matrix for dust, silica, and other agents. As a result, a subject's cumulative exposures to dust, free silica, respirable free silica, and to confounding agents were calculated.? Exposure measures for members of each set of matched cases and controls were accumulated up to the age at diagnosis of the case.

\section{ANALYSIS}

The measure of association between lung cancer and exposure to silica used in this analysis is the odds ratio(OR). ${ }^{9}$ Adjustments for the effect of other factors such as age or smoking were calculated using a multivariate regression method for matched data. ${ }^{10}$ For tests of trend, $p$ values reflect one sided probabilities. The categories of dust and silica exposure used in the analysis were arrived at by dividing the exposed subjects into thirds.

\section{Results}

Three hundred and nineteen men with lung cancer and 1358 controls were identified and their work history records were sought for the study. Three cases were excluded from the analysis, two because of no available controls, and one because of a lack of work history; six controls were excluded because of no work history. Sixty five per cent (205) of the cases were diagnosed by $x$ ray film, $18 \%$ (56) by endoscopic examination, $9 \%$ (28) by needle biopsy, $8 \%$ (25) by sputum cytology, and $0.6 \%$ (2) by clinical indications. Thirty per cent of the study subjects were from tungsten mines ( 93 cases, 400 controls), $28 \%$ from tin mines (87 cases, 371 controls), $25 \%$ from ironcopper mines ( 74 cases, 343 controls), and $18 \%$ from pottery factories (62 cases, 238 controls). Use of tobacco, predominantly cigarettes, was heavy among both cases $(93 \%)$ and controls $(80 \%)$. Cigarette use was related to risk of lung cancer in each facility type. Smokers of more than 20 cigarettes a day had an OR of 7.4 in pottery factories, 3.9 in tungsten mines, $7 \cdot 3$ in iron-copper mines, and 1.7 in tin mines. Among tin miners, pipe use was associated with a $3 \cdot 1$-fold increased risk.

Risks associated with exposure to cumulative total dust and cumulative respirable silica varied by type of facility (table 1), with the highest risks seen for tin miners, then pottery workers, whereas tungsten miners had significantly decreased risks. Iron-copper miners showed some increase with rising total dust, 
but not with respirable silica. Other exposure measures (not shown) such as average total dust, average respirable silica, and cumulative thoracic silica showed results for each facility similar to those in table 1. A semiqualitative analysis of exposure to silica based only on job title also showed similar associations with risk of lung cancer.

When risk was examined by year work was started and by number of years employed, no clearer relations emerged, except for tin miners, in which the increased risk of lung cancer was mainly among those employed before 1956.

Exposures to arsenic, PAHs, and radon were assessed for these mines and factories. Table 2 presents the age and cigarette smoking adjusted risk ratios for these agents by type of facility. Except for PAHs, there was little exposure to these agents among pottery factory workers, and a decrease in risk was associated with exposure to these agents among tungsten miners. Although exposures to PAHs and silica were correlated $(r=0.56)$ among pottery workers, hindering evaluation of their separate effects, adjustment for this confounder slightly raised rather than lowered the ORs for exposure to silica. For iron-copper miners the exposures showed no clear association with lung cancer. Among tin miners, increasing exposures to arsenic were significantly associated with risk of lung cancer, whereas exposures to PAHs were less consistently linked to increased risk. Arsenic and PAH exposures among tin miners were highly correlated with silica concentrations (arsenic, $r=0.80 ; \mathrm{PAH}, \mathrm{r}=0.80$ ), thus preventing any adjustment for these confounders in estimating the silica related risk in this group. No

Table 1 Odds ratios for lung cancer among pottery workers and miners according to level of cumulative dust and cumulative respirable silica by facility type

\begin{tabular}{|c|c|c|c|c|}
\hline \multirow[b]{2}{*}{ Measurement } & \multicolumn{4}{|l|}{$O R s^{\star}$} \\
\hline & Potteries & Tungsten mines & Iron-copper mines & Tin mines \\
\hline $\begin{array}{l}\text { Cumulative dust }\left(\mu \mathrm{g} / \mathrm{m}^{3} / \mathrm{y}\right. \\
\text { None } \\
\text { Low }(0 \cdot 1-73 \cdot 3) \\
\text { Medium }(73 \cdot 4-220 \cdot 5) \\
\text { High }(\geqslant 220 \cdot 6) \\
\text { (p for trend) } \ddagger\end{array}$ & $\begin{array}{l}1.0(11 ; 79) \dagger \\
2.0(8 ; 25) \\
1.7(17 ; 55) \\
1.5(26 ; 79) \\
\text { (NS) }\end{array}$ & $\begin{array}{l}1.0(24 ; 78) \dagger \\
1.4(39 ; 139) \\
0.5(13 ; 80) \\
0.6(17 ; 104) \\
(p=0.03)\end{array}$ & $\begin{array}{l}1 \cdot 0(17 ; 113) \dagger \\
1.3(17 ; 79) \\
1 \cdot 0(23 ; 104) \\
2 \cdot 1(17 ; 50) \\
\text { (NS) }\end{array}$ & $\begin{array}{l}1.0(15 ; 114) \dagger \\
1.4(20 ; 95) \\
3.19(26 ; 85) \\
2.69(26 ; 77) \\
(p=0.02)\end{array}$ \\
\hline $\begin{array}{l}\text { Cumulative respirable sili } \\
\text { None } \\
\text { Low }(0 \cdot 1-8 \cdot 69) \\
\text { Medium }(8 \cdot 70-26 \cdot 2) \\
\text { High }(\geqslant 26 \cdot 3) \\
(p \text { for trend }) \mp\end{array}$ & $\begin{array}{l}3 / y): \\
1 \cdot 0(11 ; 79) \\
1 \cdot 8(17 ; 53) \\
1 \cdot 5(27 ; 83) \\
2 \cdot 1(7 ; 23) \\
\text { (NS) }\end{array}$ & $\begin{array}{l}1.0(24 ; 78) \\
1.4(21 ; 81) \\
1 \cdot 1(23 ; 84) \\
0.5(25 ; 158) \\
(\mathrm{p}=0.01)\end{array}$ & $\begin{array}{l}1.0(117 ; 113) \\
1.3(31 ; 138) \\
1.3(21 ; 68) \\
0.7(5 ; 27) \\
\text { NS) }\end{array}$ & $\begin{array}{l}1.0(15 ; 114) \\
1.5(15 ; 67) \\
1.9(22 ; 82) \\
3 \cdot 19(35 ; 108) \\
(p=0.004)\end{array}$ \\
\hline
\end{tabular}

*Adjusted for age and cigarette smoking.

tNumber of cases; controls.

$\ddagger$ One sided $\mathrm{p}$ value.

$\$ 95 \%$ confidence interval excludes 1.00 .

Table 2 Odds ratios for lung cancer among pottery workers and miners according to level of cumulative exposure to arsenic, $P A H s$, and radon by facility type

\begin{tabular}{|c|c|c|c|c|}
\hline \multirow[b]{2}{*}{ Measurement } & \multicolumn{4}{|l|}{$O R s^{\star}$} \\
\hline & Potteries & Tungsten mines & Iron-copper mines & Tin mines \\
\hline $\begin{array}{l}\text { Cumulative arsenic }\left(\mu \mathrm{g} / \mathrm{m}^{3} / \mathrm{y}\right) \text { : } \\
\text { None } \\
\text { Low }(0 \cdot 1-5 \cdot 52) \\
\text { Medium }(5 \cdot 53-28 \cdot 5) \\
\text { High }(\geqslant 28 \cdot 6) \\
(p \text { for trend }) \ddagger\end{array}$ & $\begin{array}{l}1.0(62 ; 232) \dagger \\
-(0 ; 5) \\
-(0 ; 1) \\
-(0 ; 0)\end{array}$ & $\begin{array}{l}1.0(61 ; 262) \dagger \\
1 \cdot 3(19 ; 67) \\
0 \cdot 5(13 ; 71) \\
-(0 ; 1)\end{array}$ & $\begin{array}{l}1 \cdot 0(67 ; 298) \dagger \\
0.6(7 ; 48) \\
-(0 ; 0) \\
-(0 ; 0)\end{array}$ & $\begin{array}{l}1.0(15 ; 115) \dagger \\
1.4(9 ; 44) \\
1.5(13 ; 77) \\
2 \cdot 8^{\circ}(50 ; 135) \\
(p=0.004)\end{array}$ \\
\hline $\begin{array}{l}\text { Cumulative PAH }\left(\mu \mathrm{g} / \mathrm{m}^{3} / \mathrm{y}\right) \text { : } \\
\text { None } \\
\text { Low }(1 \cdot 6-108 \cdot 0) \\
\text { Medium }(108 \cdot 1-250 \cdot 0) \\
\text { High }(\geqslant 250 \cdot 1) \\
(\mathrm{p} \text { for trend }) \ddagger\end{array}$ & $\begin{array}{l}1 \cdot 0(29 ; 120) \\
1 \cdot 3(19 ; 68) \\
1 \cdot 2(4 ; 21) \\
1 \cdot 7(10 ; 29) \\
(\mathrm{NS})\end{array}$ & $\begin{array}{l}1 \cdot 0(24 ; 78) \\
1 \cdot 0(23 ; 99) \\
1 \cdot 0(28 ; 121) \\
0 \cdot 6(18 ; 103) \\
\text { (NS) }\end{array}$ & $\begin{array}{l}1 \cdot 0(17 ; 113) \\
0 \cdot 7(6 ; 59) \\
1.5(18 ; 67) \\
1.3(33 ; 107) \\
\text { (NS) }\end{array}$ & $\begin{array}{l}1 \cdot 0(15 ; 114) \\
2 \cdot 0(23 ; 106) \\
2 \cdot 7 \cdot(32 ; 97) \\
1 \cdot 8(17 ; 54) \\
(\mathrm{NS})\end{array}$ \\
\hline $\begin{array}{l}\text { Radon (working level months): } \\
\text { None } \\
\text { Low }(0 \cdot 6-38 \cdot 8) \\
\text { Medium }(38 \cdot 9-89 \cdot 4) \\
\text { High }(\geqslant 89 \cdot 5) \\
\text { (p for trend) }\end{array}$ & $\begin{array}{l}1 \cdot 0(62 ; 232) \\
-(0 ; 2) \\
-(0 ; 1) \\
-(0 ; 3)\end{array}$ & $\begin{array}{l}1 \cdot 0(34 ; 121) \\
1 \cdot 2(26 ; 108) \\
0 \cdot 7(19 ; 96) \\
0 \cdot 6(14 ; 76) \\
(\mathrm{NS})\end{array}$ & $\begin{array}{l}1 \cdot 0(51 ; 262) \\
1 \cdot 6(6 ; 17) \\
1 \cdot 4(7 ; 22) \\
1 \cdot 2(10 ; 45) \\
(N S)\end{array}$ & $\begin{array}{l}1 \cdot 0(61 ; 233) \\
0 \cdot 6(6 ; 50) \\
0 \cdot 7(9 ; 54) \\
1 \cdot 0(11 ; 34) \\
(\mathrm{NS})\end{array}$ \\
\hline
\end{tabular}

$\star † \ddagger$ See table 1 for explanations. 
Table 3 Odds ratios for lung cancer by silicosis state and facility type

\begin{tabular}{lllll}
\hline & $O R s^{\star}$ & & \\
\cline { 2 - 5 } Silicosis & $\begin{array}{l}\text { Potteries } \\
(8 ; 32) \dagger\end{array}$ & $\begin{array}{l}\text { Tungsten mines } \\
(20 ; 106) \dagger\end{array}$ & $\begin{array}{l}\text { Iron-copper mines } \\
(15 ; 37) \dagger\end{array}$ \\
\hline No & 1.0 & 1.0 & $1 \cdot 0$ & $\begin{array}{l}\text { Tin mines } \\
(37 ; 121) \dagger\end{array}$ \\
Yes & 0.5 & 0.8 & $3 \cdot 1 \ddagger$ & 1.0 \\
\hline
\end{tabular}

^Adjusted for age and cigarette smoking.

tNumber of cases; controls with silicosis.

$\$ 95 \%$ confidence intervals exclude 1.00 .

clear trend was found in the risk of lung cancer with increasing exposures to radon in the facilities, but most workers were unexposed to this carcinogen.

Table 3 shows the relation between silicosis and lung cancer by facility type. We found a significant excess of silicosis among iron-copper and tin miners with lung cancer, but not among workers in pottery factories or tungsten mines. Among the controls, silicosis was most common in tin mines (28\%), followed by tungsten mines $(23 \%)$, pottery factories $(12 \%)$, and iron-copper mines $(10 \%)$.

\section{Discussion}

In an area of the world with unusually high occupational exposure to silica, our findings provide only limited support for the hypothesis that silica induces lung cancer. The epidemiological studies to date have been inconclusive. Previous case-control studies of lung cancer have not shown clear doseresponse effects for exposure to silica, ${ }^{11-16}$ although associations between silicosis and lung cancer have been seen in some studies. ${ }^{12} 13$ Similarly, cohort studies have not shown consistent increases in lung cancer after exposure to silica, although increased risk among silicotic subjects has been commonly seen. ${ }^{517}$ There are some exceptions, including a recent cohort study of lung cancer among South African gold miners, which found a significant doseresponse gradient between risk of lung cancer and exposure to silica, but no association with silicosis. ${ }^{18}$ A recent review by Holland ${ }^{19}$ of the laboratory evidence on the carcinogenicity of silica, previously considered to be sufficient by the International Agency for Research on Cancer, ${ }^{3}$ has questioned the strength and consistency of the animal findings.

In our study of four heavily exposed occupational groups, tin miners were found to have the strongest increasing trend in risk of lung cancer with exposure to silica. This group also showed excess risks associated with inorganic arsenic and $\mathrm{PAH}$, both established pulmonary carcinogens. ${ }^{20}$ Because of the high correlation between silica, arsenic, and exposures to PAHs among these miners, it was not possible to separate the effects of one from the other. Correction for cigarette smoking, however, did not influence the association between silica and lung cancer.
The relation between silica exposure and lung cancer among pottery workers, although not reaching statistical significance, is of interest as of the four work environments pottery factories had the least amount of exposure to agents that might confound the association with silica. Adjustment for PAHs, the only major potential confounder, did not reduce the association with silica dust. An excess risk of lung cancer has been reported among pottery workers in western countries, although other exposures such as talc may be involved. ${ }^{51521}$

Except for some association with the highest dust exposure, iron-copper mines showed little relation to silica or to the other occupational exposures evaluated in the study. Tungsten miners showed a decreasing risk with increasing exposures to dust and silica. We have no ready explanation for this finding. Exposure to respirable silica in these mines was the highest of the study facilities, with $40 \%$ of the controls in the highest category of exposure ( $\geqslant 26.3 \mathrm{mg} / \mathrm{m}^{3} / \mathrm{y}$ ). Moreover, the prevalence of silicosis was high among tungsten miners with $27 \%$ of the controls having this condition.

We found conflicting evidence for the hypothesis that silicosis is causally related to lung cancer. An excess risk was found among iron-copper and tin miners, but not among tungsten miners who had the heaviest exposure to silica or among pottery factory workers who showed a positive association with silica. In a separate analysis, we found that silicosis in all four types of facility had a strong dose-response relation to silica exposure. This provides some assurance that the measures of exposure to silica and the diagnoses of silicosis used in this study were valid. The positive association between lung cancer and silicosis observed among copper-iron and tin miners may at least partly reflect ascertainment bias, because silicotic workers typically experience better medical care and record keeping than non-silicotic workers. On the other hand, some deaths among silicotic patients, particularly retirees, may be more likely to be attributed to silicosis, with under-reporting of accompanying lung cancer. In either case, it is not clear why such biases would be limited to certain occupational groups (such as copper-iron and tin miners).

Our study also provided information to estimate 
risks associated with several airborne exposures besides silica. After adjustment for age and cigarette smoking, risk of lung cancer was increased $2 \cdot 8$-fold among tin miners in the heaviest exposure category for inorganic arsenic. The levels of exposure were moderately high, averaging $1 \mathrm{mg} / \mathrm{m}^{3} / \mathrm{y}$, and thus equal to those of some United States copper smelter workers found to be at increased risk of lung cancer. ${ }^{22}$ Exposure to arsenic has also been reported to increase the risk of lung cancer among tin miners and smelter workers in another part of China. ${ }^{23}$ The increased risk among non-ferrous smelter workers has been found worldwide, but little information is available on arsenic related risks from mining operations. ${ }^{24} 25$ For both iron-copper and tin miners, inconsistent trends of increased risk were associated with estimated PAH concentrations; however, most exposures to PAHs among these miners started only recently, usually in the early 1980 s. Surprisingly, we found little association between exposure to radon and risk of lung cancer in these groups of workers, except among iron-copper miners for whom there was little dose-response gradient. Radon concentrations were not particularly high, however, with only $11 \%$ of the study subjects working in areas where cumulative exposure may have exceeded 90 working level months. It should be kept in mind that the exposure assessment for these confounding agents was less complete than that for exposures to dust and silica in the 21 mines and eight factories involved in the study.

In summary, this study of heavily exposed occupational groups has provided some evidence for a silica lung cancer association, but it was difficult to disentangle the effects of carcinogens such as inorganic arsenic or PAHs, and the dose-response relations were not consistent. Evidence for a silicosis lung cancer association was also inconsistent, with cancer risks seen among silicotic subjects in ironcopper and tin mines, but not in pottery factories or tungsten mines.

Requests for reprints to: Dr Joseph K McLaughlin, National Cancer Institute, EPN-415, Bethesda, Maryland 20892, USA.

1 Heppelston AG. Silica, pneumonconiosis, and carcinoma of the lung. Am J Ind Med 1985;7:285-94.

2 Goldsmith DF, Winn DM, Shy CM. Silica, silicosis and cancer: controversy in occupational medicine. New York: Praeger Publishers, 1986.

3 International Agency for Research on Cancer. Evaluation of the carcinogenic risk of chemicals to humans: silica and some silicates. IARC monographs 1987;42:39-143.

$4 \mathrm{McDonald} \mathrm{JC}$. Silica, silicosis, and lung cancer. Br J Ind Med 1989;46:289-91.

5 Simonato L, Fletcher AC, Saracci R, Thomas TL. Occupational exposure to silica and cancer risk. Lyon: International Agency for Research on Cancer, 1990. (IARC Sci Publ No 97.)

6 Ministry of Health, Ministry of Labour and General Trade Union of China: An implement program of treatment and prevention measures for dust-exposed workers. Beijing. Revised, 1963.

7 Dosemeci M, Chen J-Q, Hearl FJ, et al. Estimating historical exposure to silica for mine and pottery workers in the People's Republic of China. Applied Occupational and Environmental Hygiene (in press)

$8 \mathrm{Wu} \mathrm{Z}$, Hearl FJ, Peng K-L, et al. Current occupational exposures in Chinese iron and copper mines. Applied Occupational and Environmental Hygiene (in press).

9 Breslow NE, Day NE. Statistical methods in cancer research. $I$. The analyses of case-control studies. Lyon: International Agency for Research on Cancer, 1980.

$10 \mathrm{Lubin} \mathrm{JH}$. A computer program for the analysis of matched casecontrol studies. Computers and Biomedical Research 1981; 14:138-43.

11 Hessel PA, Sluis-Cremer GK, Hnizdo E. Case-control study of silicosis, silica exposure, and lung cancer in white South Africa gold miners. Am J Ind Med 1986;10:57-62.

12 Forastiere F, Lagorio S, Michelozzi P, Perucci LA, Axelson O. Mortality patterns of silicotic subjects in the Latium region, Italy. Br J Ind Med 1989;46:877-80.

13 Mastrangelo G, Zambon P, Simonato L, Rizzi P. A case-referent study investigating the relationship between exposure to silica dust and lung cancer. Int Arch Occup Environ Health 1988;60:299-302.

14 Hessel PA, Sluis-Cremer GK, Hnizdo E. Silica exposure, silicosis, and lung cancer: $\mathrm{A}$ necropsy study. $\mathrm{Br} J$ Ind Med 1990;47:4-9.

15 Meijers JMM, Swaen GMH, Volovics A, Slangen JJM, Van Vliet K. Silica exposure and lung cancer in ceramic workers: A case-control study. Int J Epidemiol 1990;19:19-25.

16 Carta P, Cocco PL, Casula D. Mortality from lung cancer among Sardinian patients with silicosis. Br J Ind Med 1991;48:122-9.

17 Amandus $\mathrm{H}$, Costello J. Silicosis and lung cancer in US metal miners. Arch Environ Health 1991;46:82-9.

18 Hnizdo E, Sluis-Cremer GK. Silica exposure, silicosis, lung cancer: A mortality study of South African gold miners. $\mathrm{Br}$ Ind Med 1991;48:53-60.

19 Holland LM. Crystalline silica and lung cancer: A review of recent experimental evidence. Regul Toxicol Pharmacol 1990;12:224-37.

20 Blot WJ. Lung cancer and occupational exposures. In: Mizell $\mathbf{M}$ and Correa $\mathrm{P}$, eds. Lung cancer: causes and prevention. Deerfield Beach, Florida: Verlag Chemie, 1984;47-64.

21 Thomas TL, Stewart PA. Mortality from lung cancer and respiratory disease among pottery workers exposed to silica and talc. Am J Epidemiol 1987;125:35-43.

22 Lubin JH, Pottern LM, Blot WJ, Tokudome S, Stone BJ, Fraumeni JF Jr. Respiratory cancer among copper smelter workers: Recent mortality statistics. J Occup Med 1981;23:779-84.

23 Taylor PR, Qiao Y-L, Schatzkin A, et al. Relation of arsenic exposure to lung cancer among tin miners in Yunnan Province, China. Br J Ind Med 1989;46:881-6.

24 Wagoner JK, Miller RW, Lundin FE Jr, Fraumeni JF Jr. Unusual cancer mortality among a group of underground metal miners. $N$ Engl J Med 1963;269:284-9.

25 Osburn HS. Lung cancer in a mining district in Rhodesia. $S \mathrm{Afr}$ Med J 1969;43:1307-12.

Accepted 15 July 1991 